Supplement of Atmos. Chem. Phys., 21, 12385-12411, 2021

https://doi.org/10.5194/acp-21-12385-2021-supplement

(c) Author(s) 2021. CC BY 4.0 License.

(c) (1)

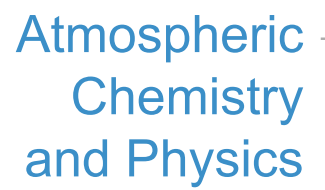

Supplement of

\title{
Fifty years of balloon-borne ozone profile measurements at Uccle, Belgium: a short history, the scientific relevance, and the achievements in understanding the vertical ozone distribution
}

\author{
Roeland Van Malderen et al. \\ Correspondence to: Roeland Van Malderen (roeland.vanmalderen@meteo.be)
}

The copyright of individual parts of the supplement might differ from the article licence. 


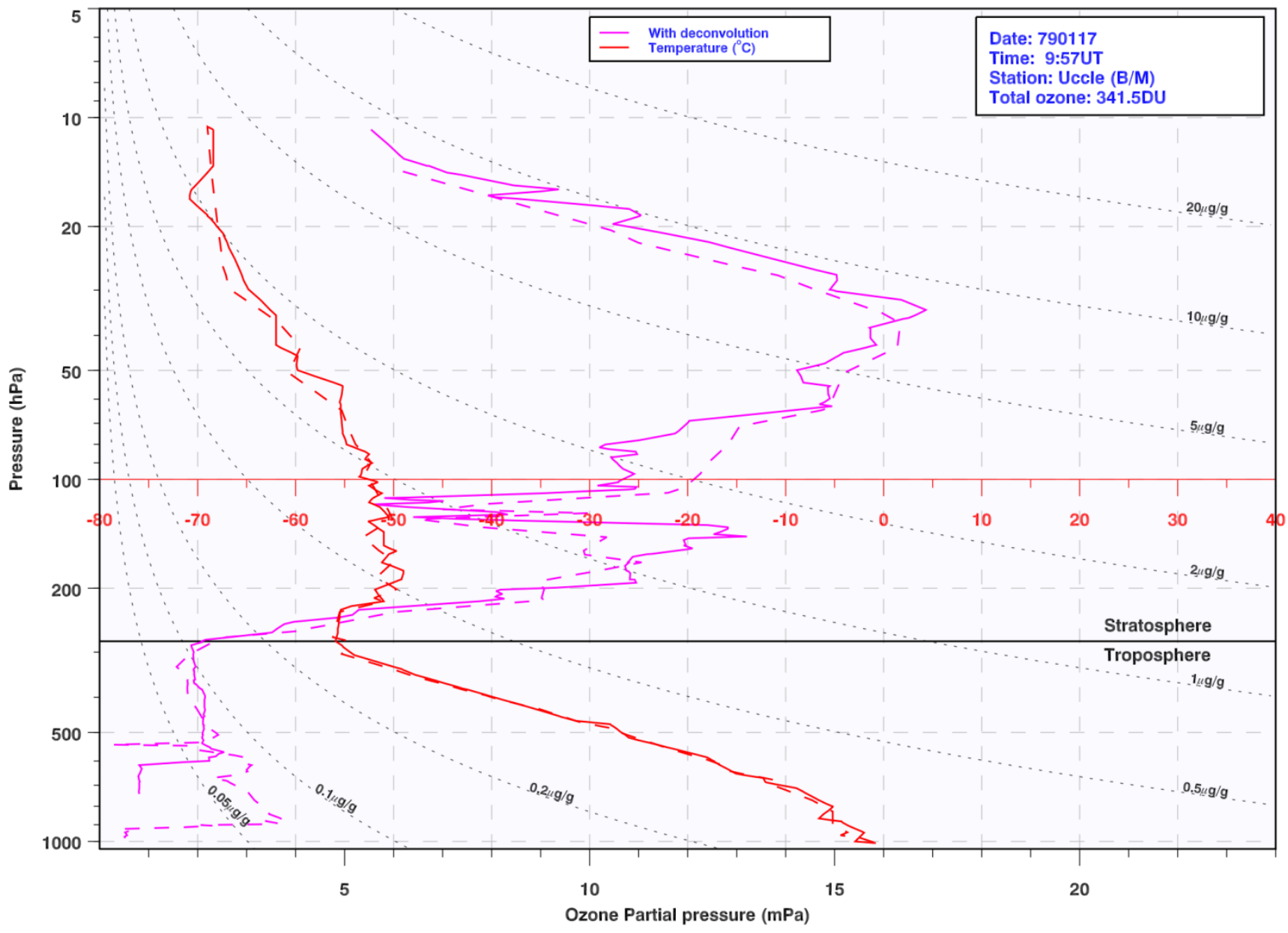

Figure S1: Example of an Uccle ozone profile in magenta, on 17 January 1979, in which the effect of the $\mathrm{SO}_{2}$ interference with the ozone measurements during the ascent of the ozonesonde (full lines) is clearly visible in the boundary layer up to the lower troposphere at about $600 \mathrm{hPa}$. In the descent ozone profile (dashed lines), the $\mathrm{SO}_{2}$ interference effect is absent until just before the landing. 


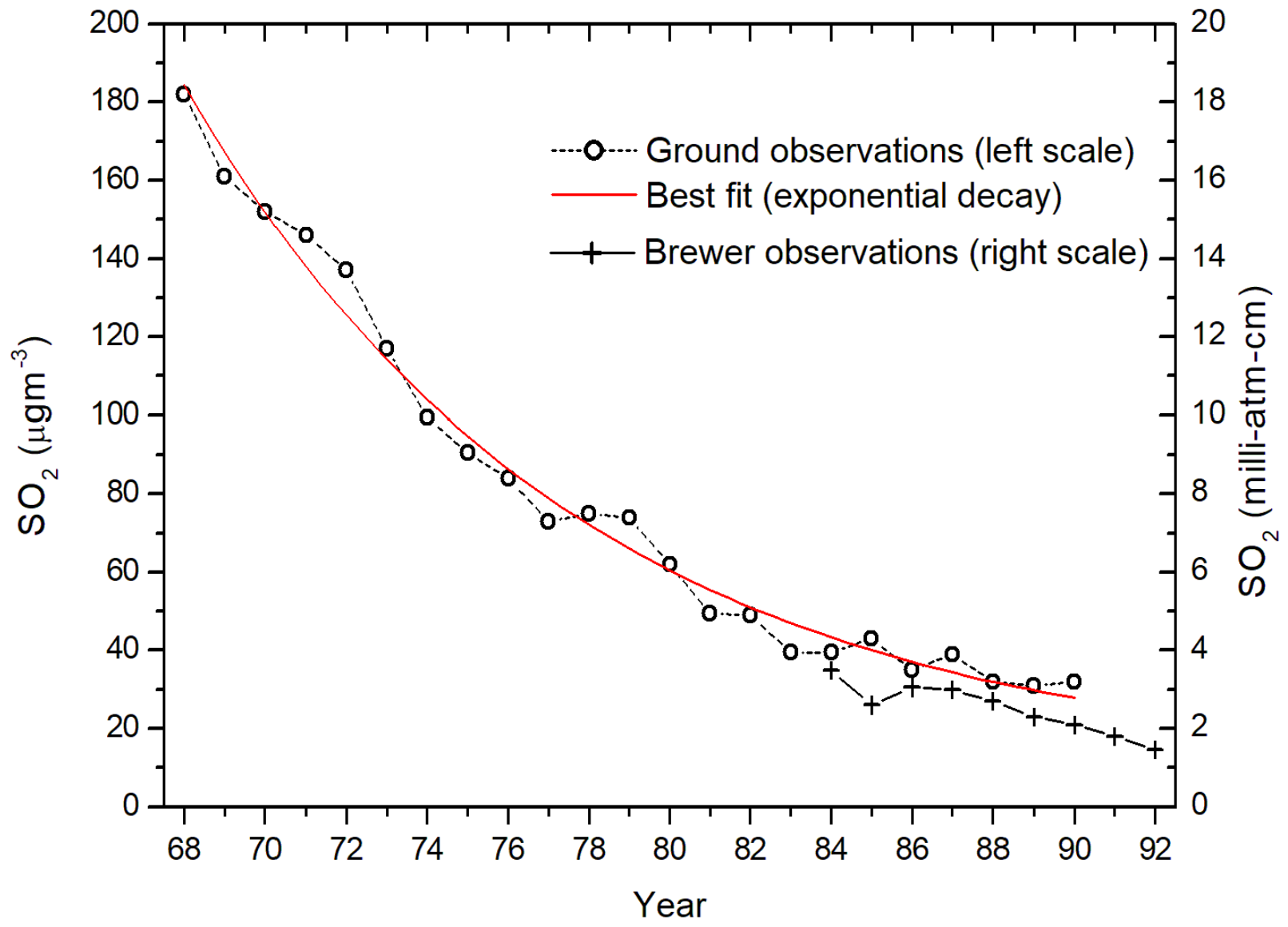

Figure S2: Variation of annual mean values of the $\mathrm{SO}_{2}$ density in the urban area of Brussels from 1968 to 1992 with the best fitting exponential curve and variation of annual mean values of the reduced $\mathrm{SO}_{2}$ amount measured with Brewer spectrophotometer 16 at Uccle since 1984 [fig. adapted from De Muer and De Backer, 1993]. 
Uccle 1969-1996

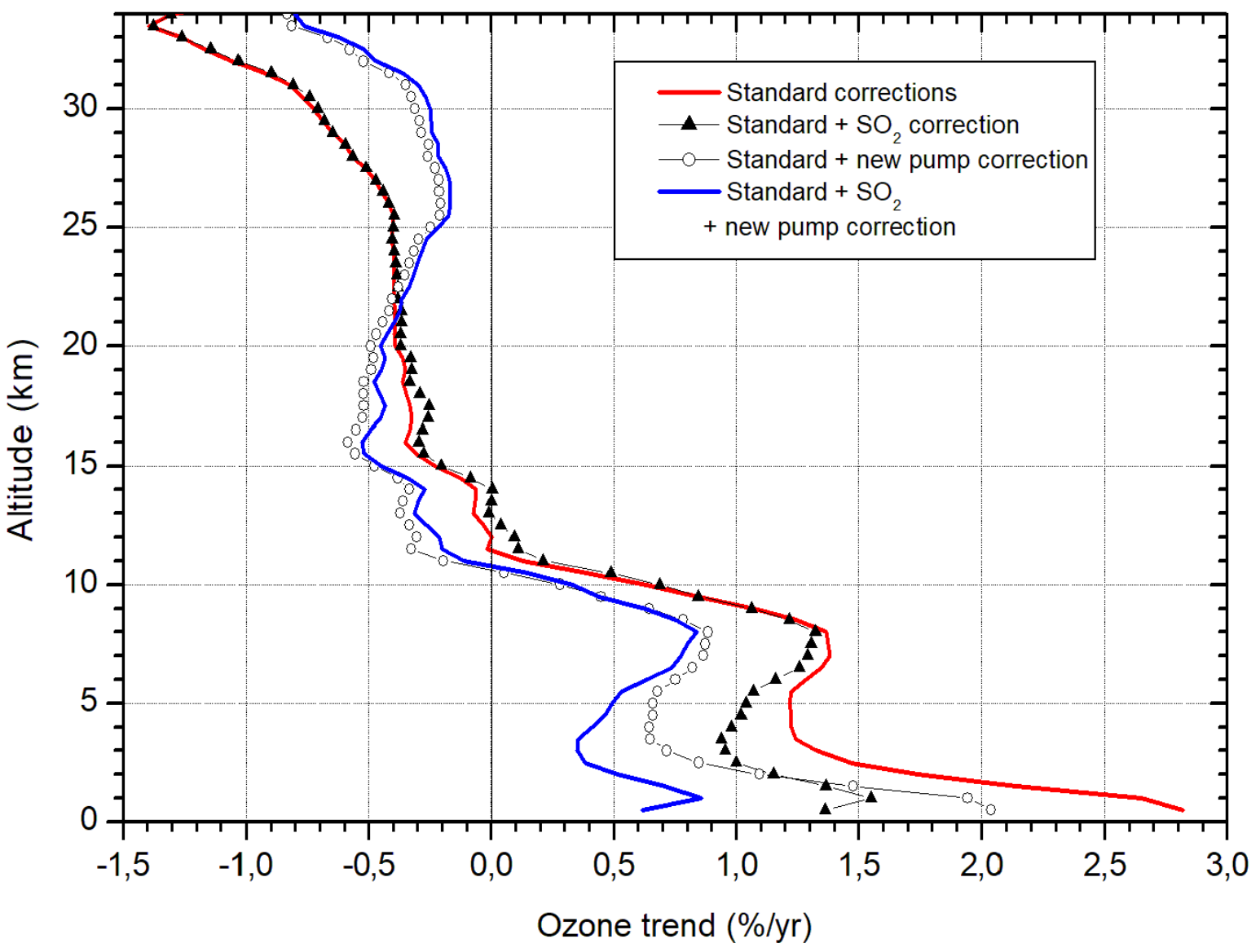

Figure S3: Profiles of calculated ozone trends at Uccle for the period 1969-1996 for different combinations of corrections applied to the BM ozonesonde time series. The "new pump correction" in the legend is described in Sect. 2.2.3. 


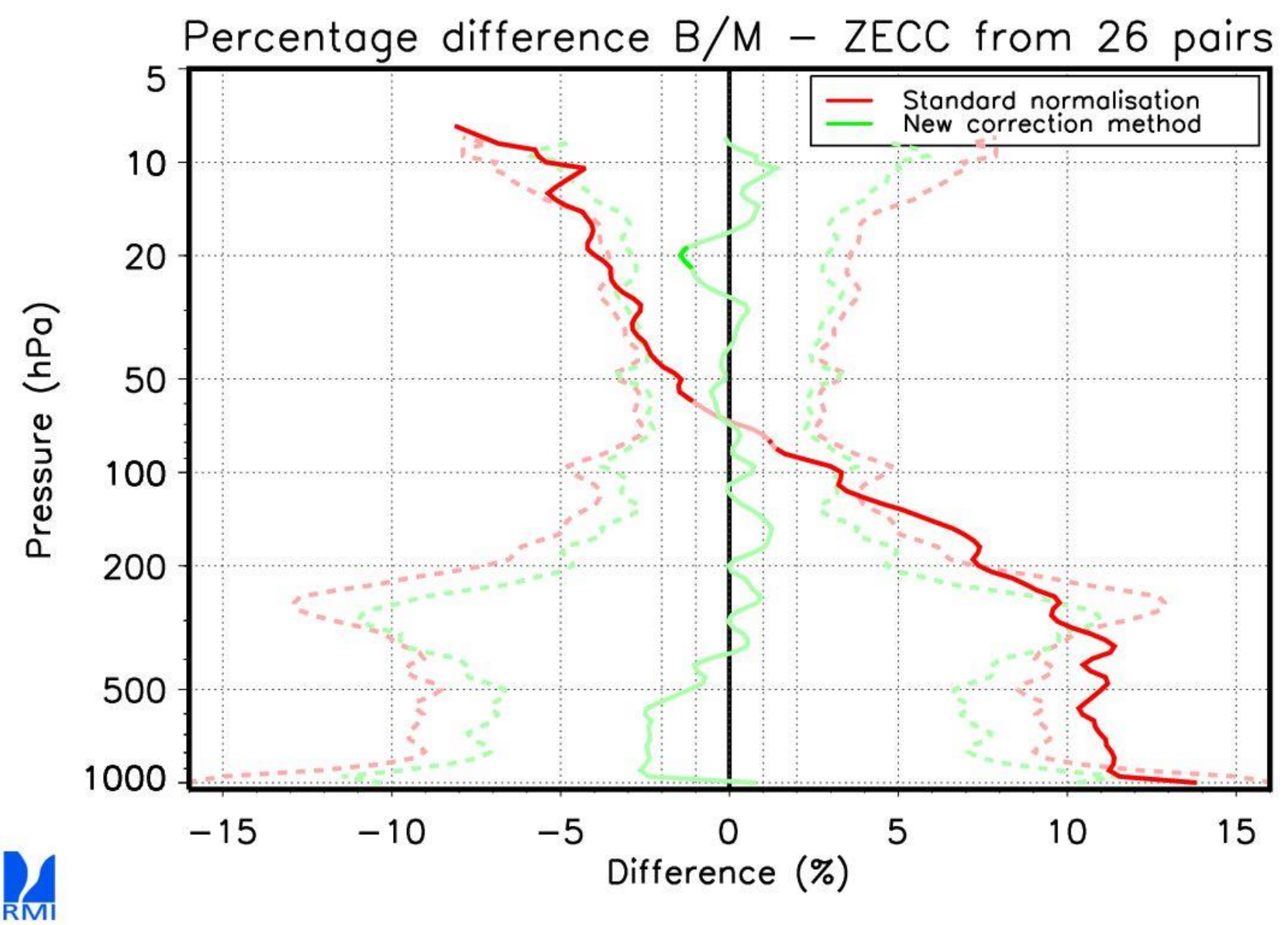

Figure S4: Mean percentage differences between ozone profiles obtained with Brewer-Mast and (En-Sci model Z) ECC sensor during dual soundings with standard correction method (red) and with the PRESTO method (green). Thick lines denote the pressure levels where the differences between the mean profiles are statistically significant. The dashed lines are the one sigma variance of the distribution of the differences [fig. adapted from De Backer et al, 1998b]. 

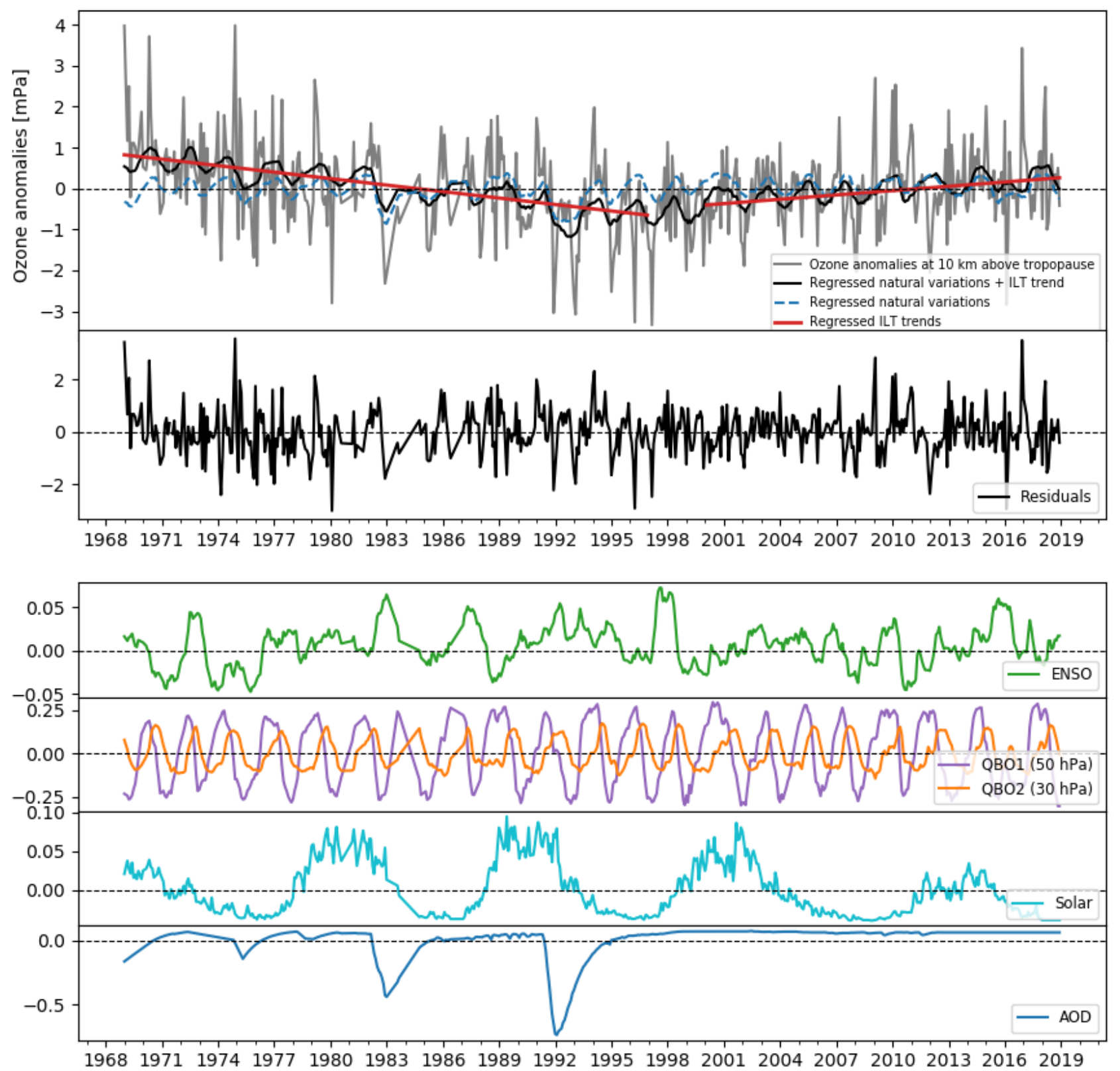

Figure S5: Terms in the LOTUS multiple linear regression model for the Uccle mean ozone concentrations in a layer $10 \mathrm{~km}$ above the tropopause height (i.e. close to the ozone peak location). The top panel shows the observed monthly anomalies of the ozone amounts in grey. The black line is the result of the full LOTUS regression model including the independent linear trends (ILTs, thick red lines). The pre-1997 trend equals $-3.8 \pm 0.6 \%$ dec $^{-1}$, the post-2000 trend $+2.5 \pm 1.0 \%$ dec $^{-1}$. The dashed blue line shows the sum of the terms of the LOTUS model without the ILTs included. The middle panel shows the residuals in the observed ozone concentrations with the full LOTUS model subtracted. The bottom panel shows the contributions of (from top to bottom) the ENSO, QBO, solar cycle, and aerosols to the reconstructed time series (blue dashed line) in the top panel. 


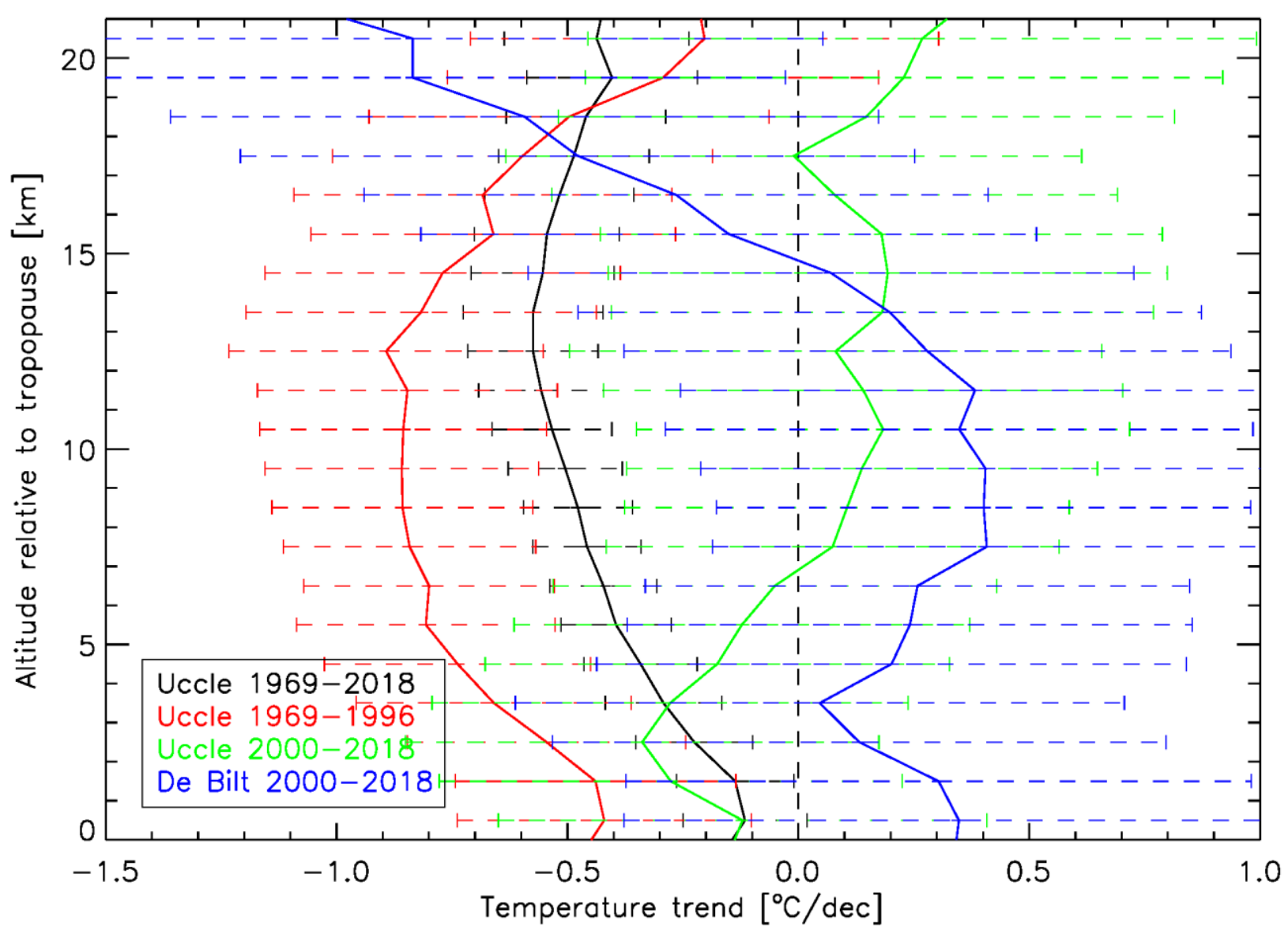

Figure S6: Vertical trends of stratospheric temperature trends at Uccle for different periods and at De Bilt (2000-2018). The trends are estimated from a simple linear regression of the monthly anomaly temperature time series, for layers of $1 \mathrm{~km}$ height, relative to the tropopause height. The error bars denote the $2 \sigma$ standard errors of the linear regression slope determination. 


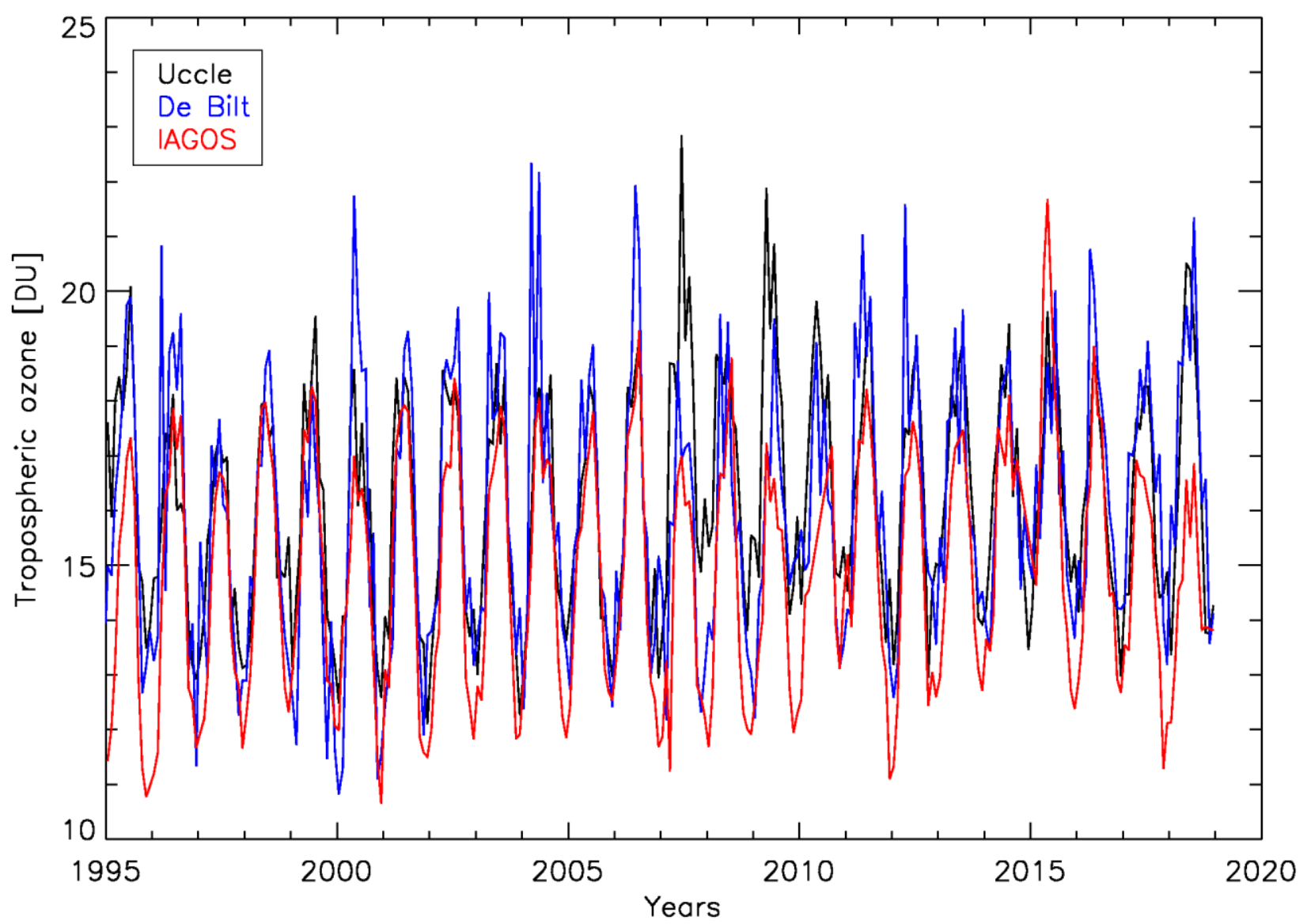

Figure S7: Monthly means of the 3-8 $\mathrm{km}$ column tropospheric ozone amounts from the Uccle and the De Bilt ozonesonde profiles and the MOZAIC/IAGOS ascent and descent profiles over Frankfurt airport for the period 1995-2018. 


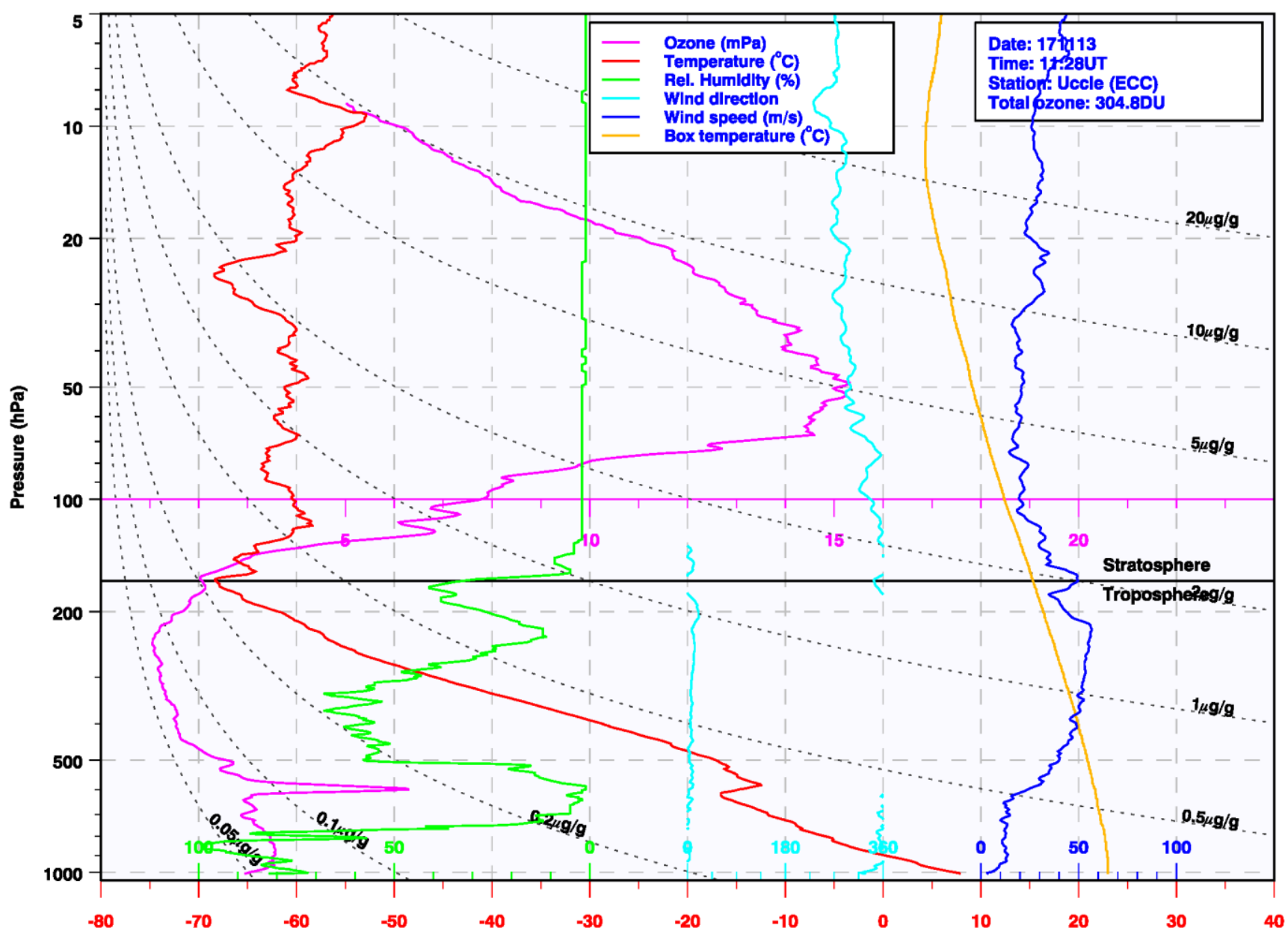

Figure S8: Example of a tropopause fold around $600 \mathrm{hPa}$ in the Uccle ozone sounding on 13 November 2017. This tropopause fold has been identified based on (i) its pronounced ozone maximum (in magenta; exact criteria: ozone mixing ratio enhanced by at least $25 \%$ compared to the climatological mean and compared to adjacent minima in the ozone profile), (ii) its very low relative humidity (in green; below 25\%), (iii) its high vertical stability (see the thermal inversion in red; vertical potential temperature gradient larger than $11.5 \mathrm{~K} / 100 \mathrm{hPa}$, its location (iv) in the vicinity of an upper tropospheric jet stream (in blue; wind speed higher than $20 \mathrm{~m} \mathrm{~s}^{-1}$ ), and (v) within an upper level front (also in blue; strong vertical wind shear above $5 \mathrm{~m} \mathrm{~s}^{-1} \mathrm{~km}^{-1}$ over at least $2 \mathrm{~km}$ in the folding region). These criteria primarily focus on the detection of tropopause folds that occur in connection to upper tropospheric frontogenesis in the polar jet stream region, as those are considered to be responsible for a large part of the mass exchange across the tropopause (see Van Haver et al., 1996, and references therein). 


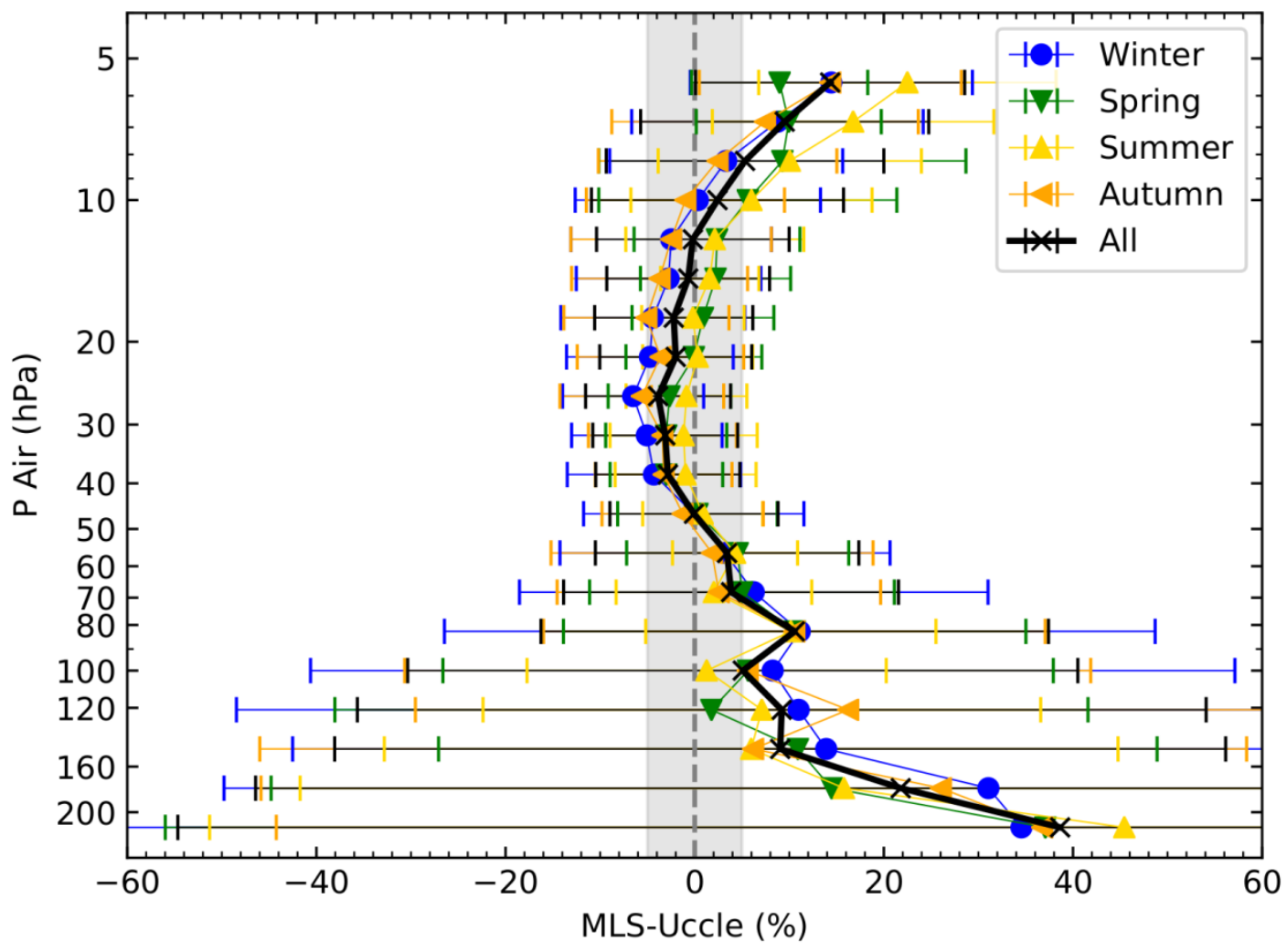

Figure S9: Relative ozone profile differences between MLS and Uccle ozonesonde for each season. The different colors correspond to each season and the black line to the overall relative difference. The error bars shown are the one sigma standard deviations of the individual differences. 


\section{Change in $\mathrm{O}_{3}$ percentiles Uccle}

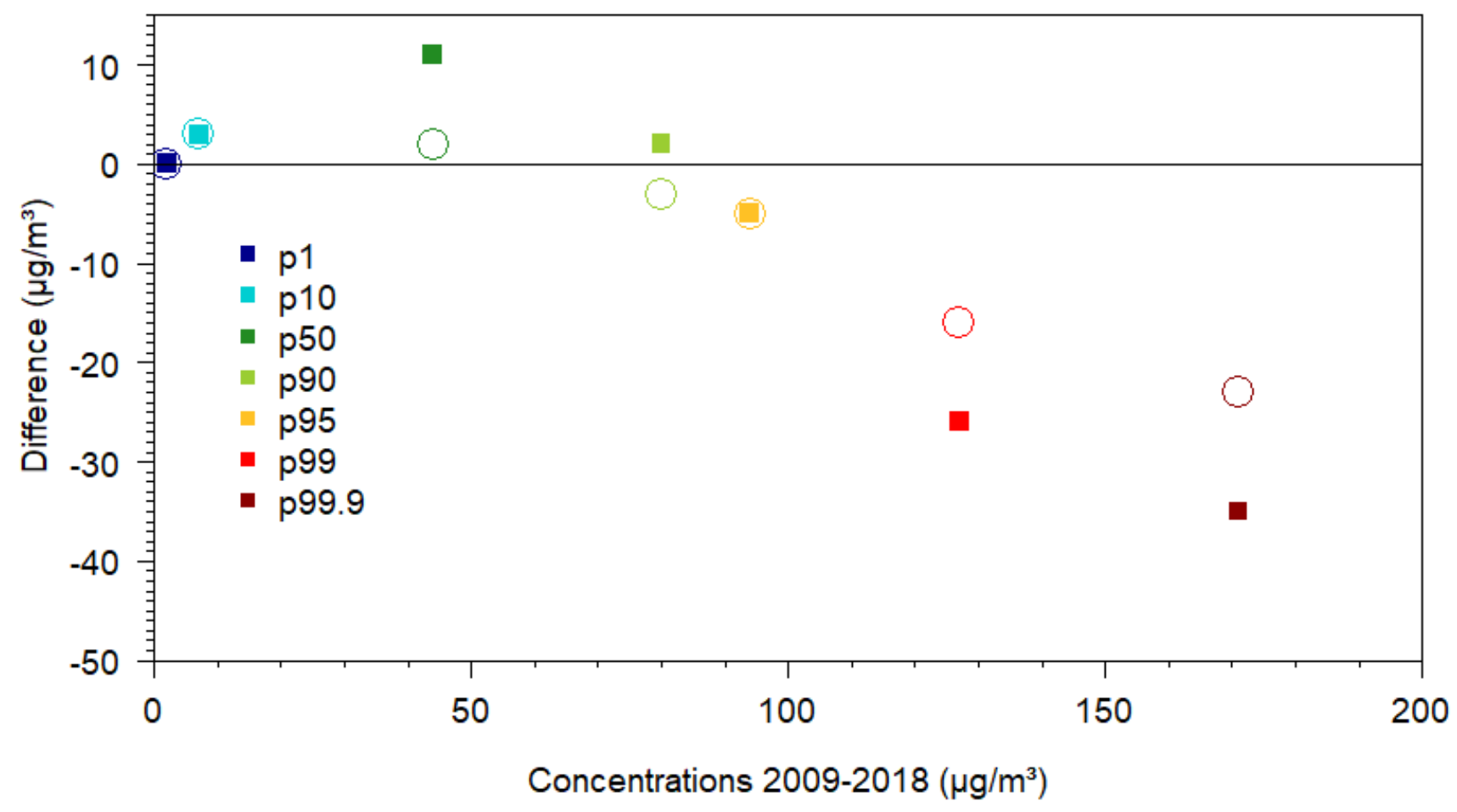

Figure S10: Differences between the surface ozone concentration percentiles at Uccle between the periods 1990-1999 and 20092018 (filled squares) and between the periods 2000-2009 and 2009-2018 (open circles), as a function of the 2000-2018 ozone concentrations. 